\title{
O ENSINO DE HISTÓRIA DO BRASIL REPUBLICANO EM UM CONTEXTO DE CRISE*
}

André Dioney Fonseca ${ }^{1}$

\begin{abstract}
A história é filha de seu tempo. Sua inquietude é pois a própria inquietude que pesa sobre nossos corações e nossos espíritos. E se seus métodos, seus programas, suas respostas mais precisas e mais seguras ontem, se seus conceitos estalam todos de uma só vez, é sob o peso de nossas reflexões, de nosso trabalho e, mais ainda, de nossas experiências vividas. (Braudel, 1992, p. 17).
\end{abstract}

Em fevereiro de 2014, recebi com muito entusiasmo a notícia de que seria docente de curso de história da Universidade Federal do Oeste do Pará (Ufopa). Minha nomeação para a carreira do magistério superior federal era, naquele momento, uma a mais entre muitas outras que pipocavam nas edições do Diário Oficial da União (DOU), tantas delas para cursos recém-criados em cidades do interior até então esquecidas no mapa do ensino superior brasileiro.

O clima geral, em 2014, era de entusiasmo. É verdade que na economia ainda colhíamos os amargos frutos da crise global do subprime de 2007-2008 e da queda dos preços das commodities globais, especialmente pelo arrefecimento da demanda chinesa. Mesmo assim, havia otimismo, pois o país parecia ter encontrado um modelo de desenvolvimento inclusivo, no qual o Estado era um destacado agente de propulsão, com capacidade de amortecer as oscilações econômicas internacionais.

Além do mais, no plano institucional, tudo era muito animador. Depois de quase todo um século XX de invulgar descompromisso com a democracia, na primeira sucessão presidencial do século XXI tivemos um importante teste de nossa saúde democrática. Na presidência, Luiz Inácio Lula da Silva, um exoperário e líder sindical de origem nordestina, reconduzido ao cargo, em 2006, pelo impulso de uma popularidade inédita e que teve como sucessora Dilma

\footnotetext{
*DOI - 10.29388/978-65-86678-64-2-0-f.37-52

${ }^{1}$ Doutor em História Social pela Universidade de São Paulo (FFLCH/USP). Atuou como professor do Curso de História da Universidade Federal do Oeste do Pará (UFOPA) entre 2014 e 2020. Atualmente é professor do Curso de História da Faculdade de Ciências Humanas (FACH) - Universidade Federal de Mato Grosso do Sul (UFMS), Campo Grande/MS, e docente vinculado ao Programa de Pós-Graduação em Educação da Universidade Federal do Oeste do Pará (PPGE/UFOPA).
} 
Rousseff, a primeira mulher a ocupar a Presidência da República, ambos, sublinhe-se, eleitos pela mesma coalisão de centro-esquerda.

Não se podem minimizar, entretanto, os efeitos das manifestações de junho de 2013, que levaram milhares de brasileiros às ruas. As jornadas, como ficaram conhecidos esses protestos, colocaram à prova o vigor democrático de nosso país em duas frentes principais. De um lado, estava o desafio lançado aos órgãos de segurança diante da robustez do movimento, e, nesse aspecto, não demorou aparecer o despreparo das autoridades, que usaram mal seus serviços de inteligência e laçaram mão de força desmedida em muitos episódios. De outro lado, o problema estava na captura dos atos multitudinários por grupos protofascistas ${ }^{2}$ minoritários, mas muito sonoros, que, além de uma pauta reacionária contra as instituições políticas e os partidos, incentivaram a hostilização de manifestantes, os quais, de maneira legítima em um quadro de normalidade democrática, expunham suas preferências partidárias ou filiação a movimentos sociais durante as marchas. Apesar disso, tudo indicava que tínhamos acertado o passo com o desenvolvimento e compreendido ser a via democrática o melhor caminho para a acomodação dos dissensos e a construção de consensos.

De 2015 para cá, contudo, vivemos os quatro mais conturbados anos desse novo século, findos os quais nos deparamos com um cenário que não admite outra classificação senão a de uma grave crise. Tivemos de tudo no fluxo temporal do quadriênio 2015-2019. O segundo mandato de Dilma Rousseff (2015-2016) teve um início bem tumultuado por uma retórica histriônica que punha em xeque o resultado das urnas. O Congresso, os grandes órgãos de imprensa e o Judiciário uniram-se em um verdadeiro mutirão contra o governo, que, acantonado, acenou para o assim chamado "mercado" com uma série de medidas que iam contra a agenda defendida nas eleições. No desespero por um fôlego de sobrevida, a Presidência vergou-se à lógica do oligopólio bancário brasileiro, nomeando para o estratégico Ministério da Fazenda um estafeta dos especuladores, o senhor Joaquim Levy. Mas foi como jogar pasto às feras; as forças golpistas, concentradas na troykea parlamentar-jurídico-midiática, estavam decididas pela deposição da senhora presidenta, estivesse ela alinhada às políticas da chamada nova matriz econômica ou ao tripé neoliberal do câmbio flutuante,

${ }^{2}$ Emprego esse termo na acepção de Henry Giroux (2004), para quem o protofascismo é uma visão social reacionária e autoritária, marcada pelo descompromisso com a democracia, com as políticas sociais e com os direitos humanos, cujos elementos definidores são: a negação da política como forma de representação das coletividades; o estabelecimento de um Estado policialesco, que prioriza as prisões, as forças policiais, a espionagem, o armamento e a militarização; a sobrevalorização do conservadorismo de fundo religioso. 
metas inflacionárias e superavit primário. Golpearam-na, ${ }^{3}$ despudoradamente, em agosto de 2016, com base em uma peça acusatória estruturada em inventividades jurídicas debatida horas a fio em sessões circenses de causar enjoo do mar em quem as acompanhava em terra firme - tomando de empréstimo a famosa alegoria kafkiana.

Logo restou nítido que essa tinha sido uma vitória do neoliberalismo, que, tendo recebido um não das urnas, recorreu ao vergonhoso atalho do golpe. O breve governo de Michel Temer (2016-2018) pôs-se, a partir de então, a serviço das associações empresariais e do ideário defendido pelos think tanks, aplicando diligentemente o abecê da cartilha neoliberal. De saída, foi aprovada a Reforma Trabalhista, em 2017, com efeitos negativos ao sistema de regulação social do trabalho e da proteção laboral. Não demorou muito para que viesse, na linha desse mesmo receituário, a aprovação do Novo Regime Fiscal (NRF), uma autêntica "jabuticaba", que, pela Emenda Constitucional no 95, condicionou o crescimento das despesas primárias aos indicadores inflacionários do ano anterior medidos pelo Índice Nacional de Preços ao Consumidor Amplo (IPCA). Sem qualquer precedente histórico e nenhuma experiência contemporânea que lhe garantisse um parâmetro de viabilidade, o NRF, também conhecido como a política do "austericídio", moldou o Estado dos sonhos do rentismo, ao priorizar o pagamento de juros, encargos ou amortizações da "dívida pública", em detrimento dos recursos destinados à infraestrutura, aos programas sociais e ao atendimento básico em áreas sensíveis, como saúde e educação.

Enquanto tudo isso ocorria, havia ainda a operação batizada de Lava Jato, cuidando de criminalizar, insidiosamente, a política e aprofundar as dificuldades econômicas do país, ao estabelecer um jeito todo próprio de interpretar as leis e um modelo de atuação pautado por vazamentos tempestivos e coletivas de imprensa espetaculosas, que faziam de cada uma de suas inúmeras fases um show pirotécnico televisionado.

Seletiva, essa força-tarefa elegeu o espaço da esquerda como terreno preferencial de suas incursões; autoritária, atropelou as premissas mais básicas do que se chama no direito de devido processo legal; oportunista, fez do justo trabalho de combate à corrupção um instrumento de ativismo político indisfarçável. Fortaleceram-se como uma entidade à parte do Judiciário, capaz, até mesmo, de fustigar em redes sociais, com desassombro nunca visto, ministros de instâncias superiores que "ousavam" reformar as sentenças de Curitiba.

3 Para uma análise detalhada dos aspectos que caracterizam o processo de impeachment de Dilma Rousseff como um golpe, ver Bessone, Mamigonian e Mattos (2016). 
E, assim, elementos explosivos, como o golpe de 2016, o desmonte do Estado pela via neoliberal, a economia no atoleiro, o desemprego galopante e as tinturas jacobinas da Lava Jato, juntos formaram um artefato que veio a estourar nas eleições de outubro de 2018, quando a sensação de revolta contra o genérico "tudo isso dấ" encontrou eco em um candidato historicamente sem expressão política e hostil às mediações institucionais democráticas. Seu figurino caricato, adornado por um discurso autoritário e radical contra inimigos fantasmagóricos, caía-lhe muitíssimo bem para a ocasião de desilusão de grande parte da população com o estamento político-partidário e de assanhamento de discursos de extrema direita em significativas frações da sociedade, incluídas aí várias instituições religiosas.

Com o candidato mais bem colocado nas pesquisas comprometido por força de lei e os partidos de esquerda desarticulados, bastou o então candidato Jair Bolsonaro acenar para o "mercado" com o anúncio prematuro de que um comissário do neoliberalismo iria ser seu ministro da Fazenda, para que sua candidatura se firmasse como viável. Uma enxurrada de fake news, espalhadas por algoritmos replicantes nas redes sociais e aplicativos; um lamentável atentado, que gerou comoção nacional, livrando-o dos debates nos quais sua atuação era constrangedoramente patética, e estava eleito, na noite do domingo de 28 de outubro de 2018, o candidato da coligação "Brasil acima de tudo, Deus acima de todos", formada pelos nanicos Partido Social Liberal (PSL) e Partido Renovador Trabalhista Brasileiro (PRTB).

E, desse modo, sob a coalisão de uma extrema direita que une pensamento ultraneoliberal na economia com reacionarismo extremado na pauta dos costumes, o Brasil de fevereiro de 2019 estava espantosamente irreconhecível àquele professor que, em conjuntura tão diferente, chegou à Ufopa em fevereiro de 2014.

Essa digressão, aparentemente distante do objetivo que se anuncia no título deste capítulo, tem o propósito de justificar minha opção em tratar o atual momento como o de uma crise e de que modo esse quadro crítico impactou a disciplina de história do Brasil republicano que venho ministrando desde meu ingresso na Ufopa. ${ }^{4}$ É evidente que o uso do termo crise não pode dar-se de

\footnotetext{
${ }^{4}$ Deve-se esclarecer que o contexto apresentado nas páginas anteriores comunica-se com uma tendência internacional e com os dilemas próprios do sociometabolismo do capital no século XXI. Não é o caso discorrermos sobre esse complexo painel, mas não será muito lembrar o enfraquecimento das democracias liberais e a ascensão de líderes autoritários eleitos democraticamente nos últimos anos mundo afora (Foa e Yascha, 2016; Lowy, 2015), bem como o rápido e contínuo declínio dos governos de esquerda na América Latina (Gonzalez, 2019). Isso tudo interligado, em escala mundial, ao de-
} 
modo inadvertido, por isso é necessário consumir algumas linhas no esforço de situar a compreensão que aqui tenho desse vocábulo tão caro ao pensamento histórico, não obstante o caráter genérico e ambíguo que o cerca, como bem destacou Randolph Starn (1971).

Levando em conta esses riscos, ressalto que o uso dessa palavra, neste capítulo, dá-se a partir de uma lógica semântica bem específica, que foge, de imediato, da rica discussão empreendida por Reinhart Koselleck (2016) a partir da díade "crítica e crise". Com intenções bem modestas, seu uso aqui serve como um indicativo do entroncamento histórico desafiador que vivemos neste momento em nosso país, ou seja, em uma acepção mais próxima ao sentido apresentado pelo Dicionário de conceitos em história, de Harry Ritter (1986, p. 79), que se refere à crise como "um curto período de desafio decisivo, uma reviravolta que determina a sobrevivência de uma pessoa, instituição ou condição, ou seu desaparecimento", 5 envolvendo situações que vão desde o urgentemente "revolucionário" até o meramente "problemático".

É certo que a observação histórica de uma situação de crise no calor dos acontecimentos traz certas implicações, pois, como indicou Randolph Starn (1971, p. 16): "Situações de crise são associadas a momentos anteriores e posteriores, então o historiador é compelido a lidar com o processo em que elas ocorrem." Assim, como protagonistas da temporalidade da crise, é-nos amputada uma dimensão muito importante, que é a do tempo posterior. Paul Ricoeur (1988, p. 2) adiciona outro elemento complicador a essa mesma questão, ao afirmar: "os protagonistas da crise ou das crises ficam, então, tentados a superestimar a originalidade da época em que vivem, a acreditar — isso é quase uma tautologia — sem precedentes".

Tendo em conta esses riscos, deve ficar claro que o objetivo deste capítulo não é analisar especificamente esse contexto de crise, mas, sim, expor o impacto dessas injunções sociais nas aulas de história do Brasil republicano que tenho ministrado desde 2014 na Ufopa, considerando que o exercício do ensino

semprego crônico estrutural, à intensificação da exploração sobre os trabalhadores e à degradação dos recursos naturais, que são os principais sintomas daquilo que István Mészáros (2002) denomina crise estrutural do capital.

${ }^{5}$ No original: " $A$ short period of decisive challenge, a turning point that determines the survival of a person, institution, or condition, or its disappearance" (tradução nossa).

${ }^{6}$ No original: "Crisis situations are relative to prior and posterior time so that the historian is obliged to deal with the process in which they occur" (tradução nossa).

${ }^{7}$ No original: "Les protagonistes de la crise ou des crises sont alors tentés de surestimer l'originalité de l'époque qu'ils vivent, de la croire — c'est presque une tautologie — sans précédent" (tradução nossa). 
de história, assim como o da pesquisa, abastece-se inapelavelmente dos problemas da atualidade. É o que aprendemos com Marc Bloch (2001, p. 65) em passagem de seu clássico Apologia da história, quando afirma que: "a incompreensão do presente nasce fatalmente da ignorância do passado. Mas talvez não seja menos vão esgotar-se em compreender o passado se nada se sabe do presente".

Recordo-me, nesse particular sentido, de uma afirmação do célebre historiador E. P. Thompson, em entrevista publicada no ano 1983, que, ao falar de sua formação, destacou os eventos traumáticos da Segunda Guerra Mundial como um "momento formativo extraordinário", em razão do comprometimento dos jovens na luta política e pelas causas populares (Thompson, 1983, p. 11). Guardadas as devidas proporções, posso afirmar que a reviravolta no cenário social e político de nosso país, nos últimos cinco anos, proporcionou um ambiente de reflexão e problematização extremamente fecundo em minha prática docente, pois, à medida que o quadro de instabilidade delineava-se e tomava a feição de uma crise, vários dos mais relevantes problemas históricos de nossa República irromperam, em invólucros diferentes, é verdade, mas desconcertantemente preservados no conteúdo essencial.

O descompromisso com a democracia, que se revela no desprezo pelo voto popular e na inclinação golpista de nossas elites; o fetiche e a instrumentalização da corrupção como forma de depreciação da política; a demonização do Estado como ente perdulário, ineficiente e irradiador da desonestidade; o ataque virulento às políticas de inclusão (as sociais e as afirmativas); o ódio de classe, perpetrado na criminalização dos pobres e miseráveis e dos movimentos sociais que os representam; o preconceito em suas várias formas de manifestação; a intromissão das entidades religiosas em assuntos de Estado; o descaso com o meio ambiente são algumas dessas flagrantes continuidades que se escancararam nesses últimos anos em nosso país.

Com o aprofundamento da crise, passei a pensar detidamente sobre meu papel como docente de um curso localizado no interior da Amazônia que tem como objetivo formar professores história. O desafio, diante de tantos imperativos sociais e políticos, estava em garantir uma formação que não estivesse alinhada à tendência de "proletarização do trabalho docente", conforme identificado por Henry Giroux (1997, p. 158), isto é, a simplificação da atuação profissional do professor como uma atividade técnico-burocrática voltada estritamente para a administração e a implementação dos programas curriculares, e não como um exercício de reflexão por meio do qual o currículo é apropriado pelo docente de forma crítica, em prol de uma "educação emancipadora", que, em termos muito resumidos, é aquela voltada ao exame crítico dos pressupos- 
tos e valores subjacentes à sua sociedade, especialmente as estruturas de poder que moldam os indivíduos (Collins e O’Brien, 2003, p. 121).

No ambiente de ataque às políticas sociais e de escalada do autoritarismo, percebi que precisava projetar em meus alunos e alunas da disciplina de história do Brasil republicano a imagem de um profissional da educação que não fosse um mero técnico, dotado de habilidades puramente instrumentais para repassar o conhecimento adquirido em sala. Era imprescindível perseguir uma trilha formativa que tivesse como horizonte a figura do professor como um intelectual reflexivo e transformador, na acepção delineada por Giroux (1997), para quem o grande problema a ser enfrentado na educação pública é a crescente força de uma ideologia instrumental e tecnocrata que persiste nos cursos de preparação para a docência.

Nessa ideologia, segundo Giroux (1997, p. 159), percebem-se "o apelo pela separação da concepção e execução; a padronização do conhecimento es colar com o interesse de administrá-lo e controlá-lo; e a desvalorização do trabalho crítico e intelectual do professor [...] pela primazia de considerações práticas". O problema posto aí é que os licenciandos são instruídos por um modelo de ensino que nada mais faz do que apresentar técnicas e metodologias de aprendizagem, desconsiderando a necessária reflexão crítica sobre questões estruturais que incidem diretamente sobre o dia a dia das escolas. No entender de Giroux:

[...] os programas de treinamento de professores muitas vezes perdem de vista a necessidade de educar os alunos para que eles examinem a natureza subjacente dos problemas escolares. Além disso, estes programas de treinamento precisam substituir a linguagem da administração e eficiência por uma análise crítica das condições menos óbvias que estruturam as práticas ideológicas e materiais de ensino. Em vez de aprenderem a levantar questões acerca dos princípios que subjazem os diferentes métodos didáticos, técnicas de pesquisas e teorias da educação, os estudantes com frequência preocupam-se em aprender o "como fazer", o "que funciona" ou o domínio da melhor maneira de ensinar um "dado" corpo de conhecimento. (Giroux, 1997, p. 159).

Em termos mais claros, o que se vê no trecho citado é uma crítica contundente ao tratamento didático-utilitarista, que prepara o futuro professor para transmitir os conteúdos em sala, mas não o instrumentaliza para enfrentar os desafios estruturais da prática docente como um cidadão ativo e reflexivo, capaz, portanto, de compreender que sua atividade profissional não depende ex- 
clusivamente dos recursos didáticos, das formas de avaliação, dos projetos pedagógicos, do currículo etc., e que a escola é, antes de tudo, um espaço em que as dimensões econômicas, culturais e sociais estão atreladas às instâncias de poder do país (Apple, 2003, 2006) e também aos grandes conglomerados econômicos do planeta (Domenech e Mora-Ninci, 2009; Laval e Weber, 2002).

A falta de clareza dessa visão joga o professor no centro do redemoinho neoliberal, imputando-lhe, pelo nexo da subjetivação concorrencial e empresarial que caracteriza a razão neoliberal (Dardot e Laval, 2016), toda a responsabilidade pelo processo educacional, pouco importando as condições profissionais e de infraestrutura oferecidas pelo Estado. Daí vêm velhos e gastos chavões, perenizados na fala dos "especialistas" do mercado e dos agentes de governo, que colocam na conta dos docentes o insucesso das redes públicas de educação, cobrando-lhes, como indica Circe Bittencourt (2018, p. 144), um "retorno aos métodos instrucionais catequéticos", que priorizam o treinamento dos alunos para os testes padronizados de avaliação.

O que geralmente não se observa nesse processo é que nisso reside o caminho para a frustração profissional de muitos jovens professores, exatamente porque a formação técnico- instrumental-didatista ensina-os a transmitir os conteúdos com os mais diferentes e estimulantes recursos pedagógicos, mas não lhes oferece os elementos teórico-críticos necessários para entender que a melhoria da educação não depende estritamente de suas atitudes pedagógicas cotidianas, ou seja, que há limitações que só podem ser superadas em outras frentes de atuação.

Não se trata, em absoluto, de empurrar nossos professores do amanhã para o conformismo, como pode parecer à primeira vista. Pelo contrário, o jovem aspirante ao magistério, quando preparado para pensar a educação em suas múltiplas dimensões, tende, por razões bem óbvias, a estar menos propenso ao desalento profissional, exatamente porque consegue entender que ele é apenas um elemento de um complexo sistema atravessado por múltiplos interesses e cujo financiamento passa longe de ser prioridade na guerra fiscal, que é sempre vencida pelos rentistas de plantão.

Tendo ciência dessa realidade, nosso docente estará mais bem preparado para enfrentar as investidas neoliberais, que, nessa era do coaching, estandardiza o empreendedorismo e o empreendedorismo de si como uma virtude de todos os campos profissionais, inclusive da educação. Sob esse prisma, a frustação alimentada pelo sentimento de que tudo se explica por sua "incapacidade profissional" dá lugar a um espírito de luta além-sala de aula, e daí temos o professor como um intelectual, um agente social, um militante da causa, que entende, 
portanto, a importância da participação nos sindicatos, nos movimentos sociais e na política, na mais abrangente concepção do termo.

A essa altura de minha argumentação, não seria imprópria uma indagação sobre o que se ganha no ensino com esse professor politizado. Bem, no campo da pesquisa histórica, não se pode dizer que essa articulação seja uma novidade. Com Fernand Braudel (1992, p. 173), aprendemos que "a história não admite senão dois planos gerais: o político, de uma parte, o social, de outra", ao que ele completa: "como na geometria descritiva, é sobre um e sobre o outro plano que é preciso projetar o corpo inteiro da história". No que diz respeito ao ensino propriamente dito, os ganhos são evidentes, se o que temos em perspectiva é uma educação de natureza emancipadora, e não puramente adaptativa, tal como defendida por Theodor Adorno (1995), autor que não desmerece a formação escolar voltada a elementos práticos da vida em sociedade, mas que vê como um grave equívoco a fixação nas experiências formativas puramente inclinadas à adaptação:

A educação seria impotente e ideológica se ignorasse o objetivo de adaptação e não preparasse os homens para se orientarem no mundo. Porém ela seria igualmente questionável se ficasse nisto, produzindo nada além de well adjusted people, pessoas bem ajustadas, em consequência do que a situação existente se impõe precisamente no que tem de pior. (Adorno, 1995, p. 143).

Lamentavelmente, é essa tendência adaptativa que vige em nossos dias pela batuta pedagógica das competências, um modelo disseminado no mundo após a extensa reforma educacional superior europeia, que culminou na assinatura do acordo conhecido como Processo de Bolonha, em 1999. A clivagem fundamental entre esses dois modos de enxergar o papel da educação está radicada no peso utilitarista da plataforma de Bolonha, levando em consideração que essa reforma nada mais foi do que uma tentativa de alinhamento da formação dos trabalhadores às novas demandas do capital, como fica bem explicado no trecho a seguir:

A educação, como está posta, baseada em um modelo de competências, configura o desenvolvimento de um conhecimento utilitarista, estratificado, que supervaloriza a preparação para o mercado de trabalho em detrimento da formação para o mundo do trabalho, no seu sentido ontológico. Dessa forma, subordina a aprendizagem às demandas do capital e transfere para o indivíduo a responsabilidade por sua empregabilidade, 
condicionada ao desenvolvimento de competências gerais e específicas traduzidas em titulações das mais diversas. (Araújo, Silva e Durães, 2018, p. 15-16).

Uma educação calçada na heurística crítico-emancipatória tem vetores muito mais abrangentes e, por isso mesmo, exige uma formação para a docência que não isole as ferramentas didáticas e técnicas de ensino e de aprendizagem - que são muito importantes - do substrato crítico que deve, invariavelmente, acompanhá-las, de modo que o professor, como intelectual transformador, possa "tornar o pedagógico mais político e o político mais pedagógico" (Giroux, 1997, p. 163).

Essa ideia, aliás, tem enorme peso no pensamento pedagógico de Paulo Freire, a quem os métodos e as técnicas de ensino não deveriam ser subestimados nem superestimados, posto que o fundamental era "a clareza com relação à opção política do educador ou da educadora [e os] princípios e valores que ele ou ela devem assumir" (Freire, 1978, p. 69).

A propósito, nesses tempos em que o vigilantismo reacionário de movimentos como o Escola Sem Partido ganha adeptos, é preciso lembrar, ainda com Paulo Freire, a "astúcia" de toda proposta que busca negar a dimensão política como parte constitutiva da educação. Sobre isso, o grande pedagogo pernambucano era enfático: "os problemas básicos da pedagogia não [são] estritamente pedagógicos, mas políticos e ideológicos" (Freire, 1978, p. 69). Henry Giroux também defende as vantagens dessa articulação entre o pedagógico e o político, quando afirma:

Tornar o pedagógico mais político significa inserir a escolarização diretamente na esfera política, argumentando-se que as escolas representam tanto esforço para definir-se o significado quanto uma luta em torno das relações de poder. Dentro dessa perspectiva, a reflexão e ação críticas tornam-se partes do projeto social fundamental de ajudar os estudantes a desenvolverem uma fé profunda e duradoura na luta para superar as injustiças econômicas, políticas e sociais, e humanizarem-se ainda mais como parte desta luta. (Giroux, 1997, p. 163).

Foi a partir dessa concepção de ensino que busquei conduzir o curso de história do Brasil republicano nesses tormentosos anos no cenário político, econômico e social de nosso país, enxergando nos alunos e alunas agentes transformadores capazes de decantar cada capítulo de nossa experiência repu- 
blicana, extraindo-lhe o que de essencial havia para compreender os acontecimentos que nos tomavam a todos de assalto.

Nesse esforço, guiava-me por alguns fatores centrais de problematização, que se destacavam por seus traços de permanência histórica, como: a) a extrema desigualdade social, que inclui, inapelavelmente, o debate sobre o sistema tributário regressivo e a máquina da dívida pública — as duas vigas mestras da concentração de renda em nosso país; b) o desemprego estrutural e a precarização do trabalho; c) os graves dilemas socioambientais; d) as formas persistentes de autoritarismo; e) a dificuldade de consolidação de um regime democrático; f) a criminalização dos movimentos sociais; g) o ataque às populações indígenas; h) a dificuldade de inclusão social da população negra e todos os problemas decorrentes dessa situação; i) a homofobia, os estereótipos e os preconceitos de gênero; j) a corrupção e sua instrumentalização pelas forças reacionárias; 1) a usurpação do poder público pelas vertentes religiosas; $m$ ) as consequências das políticas neoliberais no ordenamento político, econômico e social do país. Tudo isso sem perder de perspectiva a reflexão sempre necessária sobre o processo histórico de configuração da crise estrutural do capital (Mészáros, 2009; Piketty, 2015), já que se mostra impossível compreender nossos impasses domésticos sem considerar a posição periférica do Brasil na geometria do capitalismo global.

Diante desse lauto repertório, que obliquamente incluía outros tantos problemas avizinhados, a palavra de ordem em todas as atividades relacionadas com o curso era o exercício analítico guiado pelo estranhamento, que, como defende Carlo Ginzburg (2001, p. 41), “[...] é um antídoto eficaz contra o risco a que todos nós estamos expostos: o de banalizar a realidade". Nessa lente do estranbamento, a intenção era superar taxativamente toda forma de naturalização das mazelas sociais decorrentes da situação de crise na qual mergulhava o país, o que significa que os acadêmicos e acadêmicas eram estimulados a compreender cada fator de problematização em sua mais nítida dimensão histórica.

A importância desse exercício está em que, por esse ângulo, o futuro professor passa a entender que a permanência de uma desanimadora galeria de problemas não significa a impossibilidade de superá-los todos, já que são resultado de um construto histórico, leia-se, das decisões de nossas elites sociais e políticas, e não de um destino manifesto às avessas. Por conseguinte, esse olhar leva à negação de um leque de clichês que tentam justificar as dificuldades que enfrentamos no estabelecimento de uma sociedade mais justa e inclusiva pela simplificadora via da "essencialização", ou, caso se queira, da "absolutização" do atraso, como se ele fosse um imperativo ontogênico inscrito em nosso DNA 
social. O efeito transformador desse tipo de abordagem é que, nela, a história mostra-se como um processo aberto e, assim, nosso destino não está definido por nenhum tipo de determinismo formativo.

Para o futuro professor e professora, essa compreensão parece ser de inquestionável importância para a articulação dos temas debatidos em sala de aula, porque liberta os entraves sociais do presente de todas as algemas a-históricas, permitindo que os alunos dos Ensinos Fundamental e Médio reconheçam-se como protagonistas de uma batalha, que, por não ter um final definido, precisa ser lutada. Aí está um passo fundamental na passagem da percepção reificada da realidade para uma consciência libertadora.

Peter Mclaren e Nathalia Jaramillo (2010, p. 256) esclarecem que um fundamento inalienável da pedagogia crítica, em simbiose com o humanismo marxista, está no desenvolvimento de uma teoria ativa do conhecimento, o que significa fugir de todas as formas de determinismo, que colocam os indivíduos em condição de passividade em face da pretensa inevitabilidade de leis que se querem históricas. Para os autores, o compromisso do professor deve ser mostrar aos educandos, por meio de caminhos explicativos interepistêmicos, dialógicos e criativos, que as pessoas são capazes de mudar a realidade, mesmo diante do poder totalizador do capitalismo, que parece dar pouco ou nenhum espaço para se pensar novas formas de sociabilidade.

É nesse exercício pedagógico-crítico que floresce o humanismo democrático radical de Paulo Freire, conforme a categorização de Stanley Aronowitz (1993), uma proposta que fica muito nítida nas palavras do próprio educador, quando afirma: "Ser consciente não é, nesta hipótese, uma simples fórmula ou um mero 'slogan'. É a forma radical de ser dos seres humanos enquanto seres que, refazendo o mundo que não fizeram, fazem o seu mundo e neste fazer e re-fazer se re-fazem" (Freire, 2008, p. 70). Dessa compreensão emerge uma atitude transformadora, calcada na ideia de que os seres humanos são condicionados, mas não determinados, e que o futuro é problemático, mas não inexorável (Freire, 1996, p. 21).

Assim, nas atividades da disciplina de história do Brasil republicano, os alunos e alunas eram incentivados a refletir sobre os temas analisados, confrontando toda a variedade de axiomas que tentam explicar as dificuldades que obstaculizam nosso desenvolvimento por uma perspectiva fatalista. O comportamento das elites econômica e política, com seus consortes da classe média, no decurso de nossa história republicana, era um dos elementos que retratavam à perfeição o quanto a situação atual do país resultava de um descompromisso 
com o estabelecimento de um projeto de nação que contemplasse os interesses da majoritária parcela de compatriotas pobres e miseráveis de nosso país.

Decerto que nem tudo foram flores. O cumprimento desse programa dependia, por motivos que não exigem mais explicações, de um conjunto de textos que permitissem, ao menos, uma tomada geral de nossa centenária história republicana, com o desafio adicional de dar conta de um recorte que larga de 1889 e chega a nossos dias em uma única disciplina de 85 horas, das quais 25 são destinadas às atividades de prática de ensino. Diante dessa especificidade, que foge do que comumente se vê nas matrizes da maioria dos cursos de história, que têm duas ou até mesmo três disciplinas destinadas ao recorte republicano, vi-me na obrigação de operar uma cuidadosa seleção de referências, para evitar alguma grave omissão historiográfica.

Outra preocupação era com a leitura dos textos, pois a dificuldade de muitos acadêmicos e acadêmicas no acompanhamento da bibliografia básica foi uma questão sempre presente nas diferentes turmas para as quais ministrei essa disciplina. Nesse ponto, tendo em mente que os docentes que trabalham com a formação de professores devem assegurar-lhes o conhecimento das questões clássicas de sua área, como adverte a filósofa Marilena Chaui (2003, p. 13-14), fui bastante estrito na cobrança da leitura dos referenciais, sem jamais admitir qualquer alternativa que relativizasse a obrigatoriedade que todos tinham de ler os textos básicos da disciplina.

Outro ponto de cobrança no transcorrer da disciplina foi a conscientização dos acadêmicos e acadêmicas em relação ao compromisso que o professor de história tem de estar muito bem informado sobre o mundo à sua volta. Incentivava-os, de modo muito enfático, à leitura diária de jornais e sites noticiosos, com a instrução adicional de que essa prática era imprescindível para a atividade de docência nas escolas, já que o professor sem um mínimo de informação sobre a realidade presente não tem como pôr em prática um ensino de história problematizador, consequente, emancipador. Era nas horas destinadas à dimensão prática que essa articulação passava a ser cobrada de modo sistemático, pois aí vinham as atividades nas quais os alunos e alunas tinham de demonstrar a capacidade de conexão entre os textos e os debates em sala com a realidade atual em suas dimensões político-econômicas e socioculturais, como se no chão da escola estivessem.

Poderiam ser apresentados muitos outros interessantes detalhes sobre o que vivenciei no acidentado relevo desse tempo histórico de cinco anos em que estive à frente da disciplina de história do Brasil republicano. Tanto ensinei, mas muito mais aprendi com um público que, em sua diversidade social, de gê- 
nero, de etnia e raça, sentia nos ombros, tal como na formulação de Henry Rousso (2016 p. 301), o fardo de um "passado presente demais". Fica entre as lembranças que me dão entusiasmo para seguir adiante, nesses tempos de otimismos empalidecidos, a feliz recordação de ter participado de tantos debates nos quais, tal como descrito na epígrafe deste capítulo, nossas inquietudes e experiências vividas iluminavam os assuntos contidos nos textos, permitindo-nos compreender que os dilemas sociais do presente são históricos e que, portanto, podemos pensar em alternativas outras de sociabilidade, e por elas ir à luta.

\section{Referências}

ADORNO, Theodor W. Educação e emancipaşão. 3. ed. Rio de Janeiro: Paz e Terra, 1995.

APPLE, Michael (org.). The state and the politics of knowledge. Nova York: Routledge Falmer, 2003.

Ideologia e currículo. 3. ed. Porto Alegre: Artmed, 2006.

ARAÚJO, Christine Veloso Barbosa; SILVA, Viviane Nascimento; DURÃES, Sarah Jane. Processo de Bolonha e mudanças curriculares na educação superior: para que competências?. Educação e Pesquisa, v. 44, p. 1-18, 2018.

ARONOWITZ, Stanley. Paulo Freire's radical democratic humanism. In: MCLAREN, Peter; LEONARD, Peter (ed.). Paulo Freire: a critical encounter. Londres: Routledge, 1993. p. 8-24.

BESSONE, Tânia; MAMIGONIAN, Beatriz G.; MATTOS, Hebe (org.). Historiadores pela democracia: o golpe de 2016 e a força do passado. São Paulo: Alameda, 2016.

BITTENCOURT, Circe. Reflexões sobre o ensino de história. Estudos Avançados, v. 32, p. 127-149, 2018.

BLOCH, Marc. Apologia da história ou o ofício de historiador. Rio de Janeiro: Jorge Zahar, 2001.

BRAUDEL, Fernand. Escritos sobre a história. 2. ed. São Paulo: Perspectiva, 1992. CHAUI, Marilena. A universidade pública sob nova perspectiva. Revista Brasileira de Educaşão, Rio de Janeiro, n. 24, p. 5-15, 2003. 
COLLINS, John William; O’BRIEN, Nancy. The greenwood dictionary of education. Santa Barbara, CA: Greenwood Press, 2003.

DARDOT, Pierre; LAVAL, Christian. A nova raz̃ão do mundo: ensaio sobre a sociedade neoliberal. São Paulo: Boitempo, 2016.

DOMENECH, Eduardo; MORA-NINCI, Carlos. World Bank discourse and policy on education and cultural diversity for Latin America. In: HILL, Dave; KUMAR, Ravi. Global neoliberalism and education and its consequences. Nova York: Routledge, 2009. p. 151-171.

FOA, Roberto Stefan; YASCHA, Mounk. The danger of deconsolidation: the democratic disconnect. Journal of Democracy, n. 3, p. 5-17, 2016.

FREIRE, Paulo. A alfabetização de adultos: é ela um quefazer neutro?. Educação \& Sociedade, v. 1, n. 1., set. 1978.

- Pedagogia da autonomia: saberes necessários à prática educativa. Rio de Janeiro: Paz e Terra, 1996.

- Pedagogia do compromisso: América Latina e educação popular. Indaiatuba: Villa das Letras, 2008.

GINZBURG, Carlo. Olhos de madeira: nove reflexões sobre a distância. São Paulo: Companhia das Letras, 2001.

GIROUX, Henry. Neoliberalism's war on higher education. Chicago: Haymarket Books, 2014.

- Os professores como intelectuais: rumo a uma pedagogia crítica da aprendizagem. Porto Alegre: Artmed, 1997.

- Proto-fascism in America: neoliberalism and the demise of democracy. Bloomington, Ind.: Phi Delta Kappa Educational Foundation, 2004.

GONZALEZ, Mike. The ebb of the pink tide: the decline of the left in Latin America. Londres: Pluto Press, 2019.

KOSELLECK, Reinhart. Crítica e Crise: uma contribuição à patogênese do mundo burguês. Tradução de Luciana Villas-Boas Castelo-Branco. Rio de Janeiro: Eduerj: Contraponto, 2016.

LAVAL, Christian; WEBER, Louis (coord.). Le nouvel ordre éducatif mondial. Paris: Institut de Recherches de la FSU: Editions Nouveaux Regards et Syllepse, 2002. 
LOWY, Michael. Conservadorismo e extrema-direita na Europa e no Brasil. Serv. Soc. Soc., São Paulo, n. 124, p. 652-664, dez. 2015.

MCLAREN, Peter; JARAMILLO, Nathalia E. Not neo-marxist, not postmarxist, not marxian, not autonomist marxism: reflections on a revolutionary (marxist) critical pedagogy. Cultural Studies. Critical Methodologies, v. 10, n. 3, p. 251-262, 2010.

MÉSZÁROS, István. A crise estrutural do capital. São Paulo: Boitempo, 2009. - Para além do capital: rumo a uma teoria da transição. São Paulo: Unicamp/Boitempo, 2002.

PIKETTY, Thomas. La crisis del capital en el siglo XXI: crónicas de los años en que el capitalismo se volvió loco. 1. ed. Buenos Aires: Siglo Veintiuno Editores, 2015.

RICOEUR, Paul. La crise: un phénomène spécifiquement moderne?. Revue de Théologie et de Philosophie, n. 120, p. 1-19, 1988.

RITTER, Harry. Dictionary of concepts in history: reference sources for the social sciences and humanities. Westport, Conn.: Greenwood, 1986. n. 3.

ROUSSO, Henry. A última catástrofe: a história, o presente, o contemporâneo. Rio de Janeiro: FGV, 2016.

STARN, Randolph. Historians and "crisis". Past and Present, n. 52, p. 3-22, 1971. THOMPSON, Edward P. An interview with. In: MARHO (The Radical Historians Organization). Visions of history. Manchester, UK: Manchester University Press, 1983. p. 5-26. 